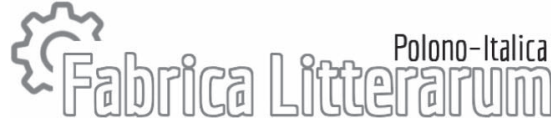

2021, nr 1 (3), s. 197-206

\title{
Kreacja androgynicznej kobiety-rycerza w Tredici canti del Floridoro Moderaty Fonte
}

\section{Abstract \\ Creation of an androgynous female knight in Tredici canti del Floridoro by Moderata Fonte}

The author of the article analyzes how Moderata Fonte characterised Risamante as an androgynous female knight in Tredici canti del Floridoro. The Italian woman writer, inspired by Matteo Maria Boiardo's Orlando Innamorato and Ludovico Ariosto's Orlando furioso, decided to write her own chivalric romance, in which she presented a new perspective on literary women warriors: Risamante is a protagonist in which female and male elements coexist harmoniously; that is not stigmatized by society, which allows her to express her androgynous personality.

Key words: androgyny, female knight, Risamante, Moderata Fonte, Tredici canti del Floridoro, Italian cinquecento, protofeminism

Słowa kluczowe: androgynia, kobieta-rycerz, Risamante, Moderata Fonte, Tredici canti del Floridoro, włoskie cinquecento, protofeminizm 
Dawniejsze białegłowy wielką sław miały, W bojach się i w naukach często obierały I wszytek świat, jak wielki, dźwiękiem napełniły Swoich dzieł zawołanych, które porobiły. Arpalice, Kamilla, bohatyrki dawne, Z dzielności są na świecie do tych czasów sławne;

Z nauk uczona Safo i Korynna słynie I dokąd świata stanie, imię ich nie zginie.

(Ariosto 1905, T. 2: 113)

W szesnastowiecznych Włoszech powstawały najważniejsze utwory europejskiego kanonu, takie jak: Orland szalony Ludovica Ariosta, Sofonisba Giana Giorgia Trissina, Ksiq̨żka o dworzaninie Baldassarego Castiglione i Jerozolima wyzwolona Torquata Tassa, dzieła mające ogromny wpływ na kolejne pokolenia literatów. Był to także okres, kiedy do głosu dochodziły wykształcone pisarki i poetki, jak: Moderata Fonte, Lucrezia Marinella, Isabella Andreini, Maddalena Campiglia, Vittoria Colonna, Veronica Gambara, Laura Terracina, Gaspara Stampa i Laura Battiferri. Na szczególne wyróżnienie zasługują lata 1580-1602 - w schyłkowym okresie włoskiego cinquecento opublikowano aż trzydzieści siedem dzieł autorstwa kobiet: dramaty duszpasterskie, utwory o treści religijnej, romanse rycerskie, a także pierwsze dzieła o charakterze protofeministycznym w formie dialogu i traktatu (Cox 2008: 131). Moderata Fonte zadebiutowała w 1581 roku swoim najsłynniejszym utworem pod tytułem Tredici canti del Floridoro (Trzynaście pieśni o Floridorze), wzorowanym na Orlandzie szalonym Ariosta. Poemat ten, zadedykowany wielkiemu księciu Toskanii Franciszkowi I Medyceuszowi i jego żonie Biance Capello, znacznie różnił się od pozostałych dzieł stworzonych przez renesansowe twórczynie. Warto zaznaczyć, że w tym okresie najczęściej pisały one utwory o charakterze religijnym, konserwatywnym lub tradycjonalistycznym. Włoska pisarka, w swoim protofeministycznym romansie dworskim, postanowiła odbiec od literackiej ekspozycji tradycyjnych ról związanych z płcią i przedstawiła nowy typ bohaterki renesansowej: androgyniczną kobietę-rycerza Risamante.

Rycerki najczęściej pojawiały się w nowożytnej literaturze europejskiej. Wprowadzanie nowego typu postaci do renesansowych eposów rycerskich sprawiło, że zaczął się formować nowy rodzaj bohaterek literackich: heroicznych wojowniczek o amazońskich rysach, będących uosobieniem etosu rycerskiego. Dwoma najpopularniejszymi romansami dworskimi, w których występowały kobiety-rycerze - Bradamanta i Marfiza - były Roland zakochany Mattea Marii Boiarda i Orland szalony Ariosta, które zresztą zapisały się w historii jako pierwsze najlepiej sprzedające się dzieła w nowożytnych Włoszech. Szczególnie utwór Ariosta cieszył się ogromną popularnością - śpiewano go na placach, omawiano podczas spotkań towarzyskich, odbywających się na dworach królewskich. Rodzice uwielbiali nadawać swoim 
córkom imiona dwóch kobiet-rycerzy z Orlanda szalonego: Bradamanta i Marfiza. Co więcej, pierwsze aktorki, którym pozwolono wystąpić na włoskiej scenie, czyli Vincenzy Armani, Vittorii Piissimi i Flaminie Romanie zdobywały sławę poprzez wykonywanie scen z eposu rycerskiego Ariosta, związanych z Bradamantą i Marfizą (Finucci, ed. 2006: 16-18). Głównie w literaturze pojawiały się liczne nawiązania do Orlando furioso - do renesansowego magnum opus Ariosta odwoływał się m.in. Teofilo Folengo w Orlandino, Edmund Spenser w Królowej wieszczek, Robert Greene w The Historie of Orlando Furioso, William Shakespeare w Wiele hałasu o nic, Luis Barahona de Soto w Las lágrimas de Angélica czy Luis de Góngora y Argote w En un pastoral albergue.

Orland szalony w czasach nowożytnych był fenomenem kulturowym, inspirującym licznych literatów, malarzy, muzyków, aktorów etc. I tak jest do dziś. Nic dziwnego zatem, że renesansowe kobiety chwyciły za pióro i również nawiązywały do dzieła Ariosta - pierwszą z nich była Laura Terracina, autorka Discorso sopra il principio di tutti i canti dell'Orlando furioso. Utwór renesansowej poetki był przedrukowywany aż trzynaście razy, od momentu wydania go w 1551 roku w Wenecji. Najbardziej udaną parafrazą zarówno Rolanda zakochanego, jak i Orlanda szalonego jest Tredici canti del Floridoro Moderaty Fonte, utwór przedstawiający losy niezwykłej bohaterki Risamante. Zdaniem Valerii Finucci:

[...] Floridoro Fonte jest przykładem pierwszego utworu, sporządzonego przez kobietę-pisarkę na wzór epickiego romansu renesansowego Ariosta i Boiarda. Nie było to łatwym przedsięwzięciem. Nie chodzi o to, że kobiety nie umiały pisać np. o scysjach, skoro książki związane z tą tematyką były popularne i łatwo dostępne. Czy też nie było trudno kobietom zagłębić się w źródła klasyczne, zwłaszcza że przez całe stulecie [XVI wiek - Z.H.] z wigorem tłumaczono wiele dzieł klasycznych na język włoski. Kobiety-pisarki również nie bały się przedstawiać scen polowań, ponieważ sokolnictwo, strzelanie i wyścigi były wtedy modnymi wydarzeniami, odbywającymi się jeżeli nie co tydzień, to nawet codziennie. Problem mógł bardziej polegać na widocznym braku wybitnych żeńskich postaci w ogólnodostępnej, drukowanej literaturze. W beletrystyce kobiety przedstawiano nieszczególnie realnie, często jako zbyt dobre albo zbyt złe. Fonte niemal od razu deklaruje, że istnieje szerszy wachlarz charakterystyk kobiet, nieobecny w literaturze, który należy uwzględnić, bowiem kobiety umiały robić wszystko to, co mężczyźni, szczególnie w przypadku, gdy były wychowywane w równości czy to na polu bitwy, czy nad biurkiem (Finucci, ed. 2006: 22; tłum. - Z.H.) ${ }^{1}$.

$1 \mathrm{~W}$ oryginale fragment ten brzmi: „[...] Fonte's Floridoro represents the first sustained effort on the part of a woman writer to pen a Renaissance epic romance on the model of Ariosto and Boiardo. The task was not easy. It is not so much that women did not know how to write of jousts, for example, since books on the subject were popular and easily available. Nor was it

199

Fabrica Litterarum Polono-Italica | 2021, nr 1 (3) 
W ostatnich latach coraz więcej literaturoznawców włoskich i anglojęzycznych zaczyna interesować się literacką spuścizną Moderaty Fonte (właśc. Modesta dal Pozzo), a sama autorka Tredici canti del Floridoro staje się prominentną postacią włoskiego cinquecento; jedną z czołowych protofeministek epoki renesansu. W Polsce pisarka pozostaje nieznana, chociaż poświęciła kilka okolicznościowych wierszy Stefanowi Batoremu (Skowron 2020: 210). Niewiele informacji biograficznych zachowało się o włoskiej pisarce, ale jej wuj, Giovanni Niccolò Doglioni, podał kilka szczegółów z jej życia w dziele pt. La Vita della Signora Modesta Pozzo dei Zorzi, nominata Moderata Fonte (Russel, ed. 1994: 128), dołączonego do pośmiertnego wydania II merito delle donne (Zasługi kobiet, 1600). Szesnastowieczna protofeministka urodziła się 15 czerwca 1555 roku w Wenecji jako córka prawnika Girolamo da Pozzo i Marietty da Pozzo. Jej rodzina należała do wyższej klasy zwanej cittadini originari (Finucci, ed. 2006: 2). Według relacji Doglioniego, gdy przyszła pisarka miała zaledwie rok, jej rodzice zmarli w wyniku dżumy (Malpezzi Price 2003: 28). Wychowaniem Fonte i jej brata Leonarda zajęła się ich babka ze strony matki Cecilia de'Mazzi i jej drugi mąż Prospero Saraceni. Autorkę Tredici canti del Floridoro wysłano do klasztoru w Santa Marta, aby nauczyła się pisać i czytać (Finucci, ed. 2006: 2). Miała niezwykłą pamięć oraz inteligencję i z tego powodu nazywano ją cudownym dzieckiem. W wieku 9 lat lat wróciła do domu babki, gdzie korzystała z książek i wiedzy Prospera Saraceniego. Dodatkowo autorka /l merito delle donne codziennie pytała brata o to, czego się nauczył w szkole - w taki sposób nauczyła się czytać i pisać po łacinie, rysować, śpiewać, grać na lutni i klawesynie. Giovanni Nicolò Doglioni poprosił Fonte, aby zamieszkała z nim i jego żoną. Uczył ją, zachęcał do pisania i pomógł jej opublikować pierwsze dzieła, wydane pod pseudonimem Moderata Fonte. 15 lutego 1582 roku kobieta renesansu wyszła za mąż za Filippo de' Zorzi, z którym miała czwórkę dzieci (Malpezzi Price 2003: 28-35). Zmarła przy porodzie czwartego dziecka - w 1592 roku, i pochowano ją w bazylice Santa Maria Gloriosa dei Frari, znajdującej się w Wenecji (Finucci, ed. 2006: 4-5).

W renesansowym eposie rycerskim Fonte głównym bohaterem nie jest tytułowy Floridoro, którego włoska pisarka wprowadza do swojej opowieści dość późno, lecz Risamante, postać występująca w niemal każdej pieśni (Finucci, ed. 2006: 10).

too difficult for women to dig into classical sources, since many classics had been vigorously translated into Italian throughout the century. Women writers were not put off by representations of scenes of hunting either, since falconry, shooting, and races were popular weekly, if not daily, events. The problem was rather the noticeable lack of successful female models offered by the available printed literature. Women in fiction were hardly real, often either too good or too bad. Fonte declares almost right away that there was, however, a wider range of feminine facets unrepresented in literature that needed to be accounted for, since women could do all things men did when the circumstances of their upbringing were equal, whether on the battlefield or the writing table" (Finucci, ed. 2006: 22).

200

Fabrica Litterarum Polono-Italica | 2021, nr 1 (3) 
Początkowo, w Canto I, „guerriera” jest bohaterką bez tożsamości (Malpezzi Price 2003: 107), bezimiennym rycerzem, przybywającym do Grecji w celu podjęcia walki z Macandrem. Dopiero w Canto II, gdy zdejmuje hełm, przestaje być postacią anonimową - narrator dostarcza czytelnikowi informacji o jej przeszłości. Okazuje się, że Risamante ma siostrę bliźniaczkę Biondaurę; jest dawno zaginioną księżniczką Armenii:

[...] questa donzella [...]

Che Risamante per nome s'appella,

Con la bella Biondaura a un parto nacque.

Figlie del re d'Armenia e questa e quella,

Pari in tutto fra lor come al ciel piacque,

Eccetto ch'una è molle e delicata

E l'altra va come guerriero armata. (Canto II, stanza XXX)

Jako dziecko rycerka została porwana przez czarodzieja Celidante, który ukrywał ją przez wiele lat w zamku, znajdującym się na środku oceanu: „[...] le stelle / La inclinavano ad opre alte e leggiadre" (Canto II, stanza XXXI). Mężczyzna wychowywał bohaterkę jak własną córkę, ucząc ją sztuki rycerskiej i jednocześnie przygotowując ją do spełnienia osobistego przeznaczenia:

Per questo non rimase Celidante

Con diligenza e con paterno amore

D’allevar la fanciulla Risamante,

Di cui previsto avea l'arte e 'I valore,

Tal ch'ella poscia a tutti gli altri inante

Andò nell'arme e n'ebbe eterno onore. (Canto II, stanza XXXII)

Dopiero po siedemnastu latach Risamante dowiedziała się o swoim królewskim pochodzeniu. W podobny sposób została przedstawiona historia rekonstruująca lata dzieciństwa Ruggiero, bohatera Orlanda szalonego Ariosta. Kolejno: traci rodziców; ma siostrę bliźniaczkę Marfizę, dorasta w zamku, znajdującym się na szczycie (monte di Carena) w Afryce i jest wychowywany przez czarnoksiężnika Atlanta, który uczy go, „jak zostać rycerzem”. Widoczne jest tutaj nawiązanie do arturianizmu w jednej z wersji legend mały Artur został przekazany w ręce Merlina, który dbał o to, aby przyszły król Brytanii został wychowany na prawego rycerza (Berthelot 2003: 47). Co więcej, po śmierci króla Bana, ojca Lancelota, bohater cyklu rycerskich opowieści okrągłego stołu jako niemowlę zostaje porwany przez Vivianę. Lancelot mieszka z nią w jej pałacu na dnie jeziora, aż do 18. roku życia (Makowiecki 2000: 420). Według starofrancuskiego cyklu Lancelot-Graal, powstałego w latach 1215-1235, Pani z Jeziora szkoli Lancelota i przygotowuje go do podjęcia roli rycerza.

201

Fabrica Litterarum Polono-Italica | 2021, nr 1 (3) 
Risamante najbardziej przypomina kobiecą wersję króla Artura, kreowaną przez Fonte jako ucieleśnienie platońskiego mitu androgynii - bez względu na sytuację rycerka nieustannie utrzymuje złoty środek w swoim kobieco-męskim usposobieniu. Jej dychotomiczna natura jest uwydatniana szczególnie podczas bitew i turniejów. Na końcu Canto I Risamante, przedstawiona jako tajemniczy rycerz, postanawia wziąć udział w turnieju, odbywającym się w Grecji. W początkowych oktawach Tredici canti del Floridoro czytelnik dowiaduje się o przyczynie podjętych walk: przed królem Cleardo, obok którego znajdują się jego córka Celsidea, żona, damy dworskie i greccy bohaterowie, staje Macandro opisany jako król Partii i gigant, przybywający z Armenii do Grecji w celu obrony honoru swojej ukochanej, księżniczki Biondaury:

Or mentre egli in Armenia alla gran corte

Beato serve e altier di tanta dama [Biondaura],

Ode quanto gran biasmo il grido apporte

Di questa greca a lei ch'egli tanto ama,

E gli accende una rabbia in cor sì forte

Che (se potesse) uccideria la fama,

Pur, quando altro non può, disegna almeno

Sfogar nel regno acheo tanto veleno. (Canto I, stanza XII)

Przywołany passus, w którym pojawia się Macandro przypomina scenę z Rolanda zakochanego Mattea Marii Boiarda, w której Karol Wielki, otoczony rycerzami i dworzankami, widzi, jak z daleka czterech gigantów wchodzi do sali królewskiej (Finucci, ed. 2006: 59). Macandro również chciał udowodnić, że Biondaura jest nie tylko piękniejsza od Celsideii, ale także nie ma sobie równych pod względem urody. W taki sposób rozpoczęły się turnieje, trwające trzy dni; podczas których wielu rycerzy walczyło przeciwko królowi Partii, stając w obronie urody przyszłej władczyni Grecji, Celsidei. Jednakże Macandro wygrywał za każdym razem i tak jak Rodomonte z Orlanda szalonego zbierał tarcze przegranych, traktując je jako rodzaj trofeum. Sytuacja zmieniła się w trzecim dniu turniejów, kiedy pojawił się „Un cavallier ch'alla ventura andava” (Canto IV, stanza II) gotowy do pokonania króla Partii. Tym rycerzem okazuje się Risamante, co zostaje ujawnione dopiero w Canto II - Fonte celowo używa wyłącznie zaimków rodzaju męskiego, aby nie doszło do przedwczesnego zdemaskowania prawdziwej tożsamości bohaterki. Od momentu wkroczenia Risamante na literacką scenę, jej postać zostaje przez autorkę II merito delle donne poddana „permanentnej apoteozie” i zaczyna ucieleśniać archetyp idealnego rycerza:

Il cavallier parea gagliardo e franco

Alla presenza, e sopra ogn'altro ardito.

202

Fabrica Litterarum Polono-Italica | 2021, nr 1 (3) 
Era sua insegna in verde scudo un bianco

Giglio, era verde e candido il vestito. (Canto II, stanza V)

Risamante odznacza się siłą i odwagą; posiada zieloną tarczę, na której widnie symboliczny emblemat: biała lilia. Warto wspomnieć o tym, że w romansach dworskich kolor biały był często używany do reprezentowania kobiet-wojowników (Finucci, ed. 2006: 72). Fonte przedstawia swoją bohaterkę w podobny sposób do Ariosta, który w Orlandzie szalonym początkowo nie ujawnia prawdziwej płci Bradamanty, opisując ją jako rycerza, odzianego w szaty o śnieżnym kolorze:

A wtem mu się ukazał, gdzie beł wąwóz ciasny,

lle mógł znać z postawy, jakiś rycerz straszny;

Szata na niem białością mogła zrównać z śniegiem,

Kita także u hełmu, a biegł wielkiem biegiem.

(Ariosto 1905, T. 1: 16)

Przybycie Risamante do Grecji jest niezmiernie istotne - przychodzi w sukurs ludowi greckiemu, witającemu ją z otwartymi ramionami: „A pena entrò che gli fur cento al fianco / Che gli fero accoglienza e grato invito" (Canto II, stanza V). Kobieta-rycerz, będąca „cortese e d’animoso core” (Canto II, stanza VI), oferuje pomoc zbrojną królowi Cleardo, „che l'accettò di core” (Canto II, stanza VI) i tak dochodzi do pojedynku pomiędzy nią a Macandrem. Podczas turnieju Risamante wykazuje się znajomością sztuki rycerskiej, niezwykłą tężyzną fizyczną i wytrwałością. Jest jedynym rycerzem, któremu udaje się pokonać Macandra:

Già tutto il fatto avea dalla muraglia

Scorto Cleardo e tutta insieme Atene,

Però che da vicin fu la battaglia

Fatta, e ciascun potea mirarla bene.

Onde, come a quel re la Parca taglia

Lo stame e 'I mira spento in sull'arene,

Scende dal muro e corre ogni persona

E 'I vincitor di lode orna e corona. (Canto II, stanza XXIII)

Gdy Risamante zdejmuje hełm, nikt nie jest zdziwiony, że rycerzem, który pokonał króla Partii, okazuje się kobieta. W tej scenie dochodzi do ostentacyjnej prezentacji androgynii. Hełm rycerki symbolizował internalizację kobieco-męskiego psyche bohaterki, a dopiero gdy go ona zdejmuje, daje wyraz swojej osobowości androgynicznej. W utopijnym świecie Tredici canti del Floridoro, eksternalizacja dychotomicznego usposobienia Risamante nie spotyka się z potępieniem ze strony innych osób. Ludzie zgromadzeni podczas turnieju pomiędzy nią a Macandrem, są 
zaintrygowani jedynie tym, że wygląda tak samo jak ukochana króla Partii, księżniczka Biondaura. Chociaż rycerka ma urodę podobnej do Laury z Canzoniere Petrarki, to autorka Tredici canti del Floridoro nie dodaje do swojego dzieła mizoginistycznych uwag, dzięki czemu przedstawia Risamante jako niezależną kobietą, która wykorzystując inteligencję i umiejętności bitewne (Malpezzi Price 2003: 107), walczy o tron Armenii. W taki sposób za sprawą Risamante szesnastowieczna pisarka chciała pokazać czytelnikom, że w renesansowym, patriarchalnym społeczeństwie istnieją kobiety, które potrafią być samodzielne i gdy dostają szansę na zdobycie wykształcenia, mogą odnosić sukcesy (Malpezzi Price 2003: 109-110). W Tredici canti del Floridoro bohaterka nie jest piętnowana przez mężczyzn, wręcz przeciwnie - każdy z nich jest pod wrażeniem jej siły fizycznej i okazywanego heroizmu. Poza tym podczas pojedynku z królem Babilonii Cloridabello, jeden z wojowników nazywa Risamante najdzielniejszym rycerzem świata:

- Quel cavallier dal lato di levante

Ch'in verde scudo arreca il giglio bianco

È la nostra regina Risamante,

Che non ha 'I mondo un cavallier più franco. (Canto XIII, stanza LI)

W opisie walki Risamante ze smokiem, Fonte wyeksponowała harmonijnie koegzystujące z sobą cechy kobiece i męskie w rycerce. Tuż po wygranej bitwie z Macandrem bohaterka wyrusza do Azji. Podczas swojej podróży znajduje się nieoczekiwanie w „bel giardin” - ogrodzie pełnym akantów, jaśminu, narcyzów, krokusów i krzewów różanych, przypominającym celtycki Avalon. W tej pięknej scenerii napotyka smoka, który "Salta dei cespi sibilando fuori / E strugge col suo fiato l'erbe e i fiori" (Canto III, stanza XIII). W trakcie walki bohaterka ponownie prezentuje swoje umiejętności rycerskie: smok stara się wyrządzić jej krzywdę, lecz nieskutecznie - paladynka doskonale potrafi się bronić i ostatecznie udaje jej się zgładzić bestię. Fonte uwydatnia waleczność Risamante, porównując ją do księcia fenickiego Kadmosa, znanego z poskromienia smoka w Tebach. Podobną scenę do tej z Tredici canti del Floridoro, znajdujemy w mitologii irlandzkiej. W Cyklu Feniańskim pojawiają się opowieści - odnoszące się do realiów III wieku n.e. mówiące o mitycznym wojowniku Fionnie mac Cumhailu, który tak jak Risamante stracił ojca, został po urodzeniu oddzielony od matki, był wychowywany przez druidkę Bodhmall oraz wojowniczkę o imieniu Liath Luachra i słynął z zabijania smoków. Warto wspomnieć o tym, że topos walki z wężem/smokiem sięga czasów starożytnych - w religii mezopotamskiej, w babilońskim poemacie Enuma eliš jest mowa o walce Marduka, najważniejszego boga panteonu babilońskiego z boginią Tiamat, często przedstawianą jako wąż morski lub smok. Ten stary topos Fonte wykorzystała w swoim eposie, poddając go jednak pewnej modyfikacji - w Tredici

204

Fabrica Litterarum Polono-Italica | 2021, nr 1 (3) 
canti del Floridoro to kobieta walczy ze smokiem. Tutaj włoska pisarka poprzez „androgynizację Risamante” pokazuje, że nie ma zasadniczych różnić pomiędzy przedstawicielami obu płci; kobiety i mężczyźni mogą być obdarzeni tymi samymi predyspozycjami fizycznymi.

Risamante wyróżnia się na tle innych literackich kobiet-rycerzy. Jest postacią androgyniczną, która nie musi postępować zgodnie z normami społecznymi - wszak zostaje wychowywana z daleka od patriarchalnego środowiska (Aydoğdu Çelîk 2019: 374-375). Fonte, kreując taką postać jak Risamante, chciała pokazać, że bohaterka nie musiała tłumić swojej kobiecości, aby osiągnąć wyznaczone cele. Protagonistka nie wyrzeka się swej kobiecości, nie dominują w niej też męskie cechy charakteru posiada typ osobowości „zintegrowanej”, jednając harmonijnie cechy kulturowo przypisywane kobietom i mężczyznom (Aydoğdu Çelîk 2019: 376-377).

\section{Bibliografia}

Ariosto Ludovico (1905): Orland szalony. Tłum. P. Kochanowski. T. 1-2. Kraków.

Aydoğdu Çelîk Merve (2019): Androgyny in Moderata Fonte's Tredici canti del Floridoro. „Selçuk University Journal of Faculty of Letters”, vol. 36, nr 2.

Berthelot Anne (2003): Król Artur i rycerze Okrqgłego Stołu. Tłum. A. Choińska. Warszawa.

Cox Virginia (2008): Women's Writing in Italy, 1400-1650. Baltimore.

Finucci Valeria, ed. (2006): Floridoro: A Chivalric Romance. Transl. J. Kisacky. Chicago. Makowiecki Andrzej (2000): Słownik postaci literackich. Warszawa.

Malpezzi Price Paola (2003): Moderata Fonte: Women and Life in Sixteenth-century Venice. Madison.

Russell Rinaldina, ed. (1994): Italian Women Writers: A Bio-bibliographical Sourcebook. Westport.

Skowron Maja (2020): Kobiece reguły gry. Spór o kobiety w dialogu "Il merito delle donne” Moderaty Fonte. „Terminus”, vol. 22.

\section{Abstract \\ Creazione di una cavaliere androgina in Tredici canti del Floridoro di Moderata Fonte}

L'autrice dell'articolo analizza come Moderata Fonte abbia creato il personaggio della guerriera Risamante nei Tredici canti del Floridoro. La scrittrice italiana, attingendo alle

205

Fabrica Litterarum Polono-Italica | 2021, nr 1 (3) 
conquiste delle epoche precedenti e ispirandosi principalmente all'Orlando innamorato di Matteo Boiardo e all'Orlando Furioso di Ludovico Ariosto, ha deciso di scrivere la propria epopea, in cui ha presentato un nuovo tipo di eroina rinascimentale: un cavaliere androgino, con caratteristiche tipiche degli stereotipi sia femminili, che maschili.

Parole chiave: androginia, Risamante, Moderata Fonte, Tredici canti del Floridoro, cinquecento italiano, protofemminismo 